\title{
The effect of porosity and microcracking on the thermomechanical properties of cordierite
}

\author{
A. Shyam ${ }^{1 *}$, G. Bruno ${ }^{2}$, T. R. Watkins ${ }^{1}$, A. Pandey ${ }^{1,3}$, E. Lara-Curzio ${ }^{1}$, C. M. Parish ${ }^{1}$, R. \\ J. Stafford ${ }^{4}$ \\ 1 - Materials Science and Technology Division, Oak Ridge National Laboratory, TN-37934, USA \\ 2 - BAM Federal Institute for Materials Research and Testing, D-12200 Berlin, Germany \\ 3 - Reliability Division, Rolls Royce LG Fuel Cell System Inc., North Canton, OH-44720, USA \\ 4 - Ceramics and Catalyst Technology, Cummins, Inc., Columbus, IN-47201, USA
}

\section{Abstract}

The effect of porosity and microcracking on the mechanical properties (strength, fracture toughness, Young's modulus, and fracture energy) and thermal expansion of diesel particulate filter (DPF) grade cordierite materials has been investigated. A method to deconvolute the effect of porosity and microcracking on Young's modulus is proposed. In addition, the microcrack density and the pore morphology factor are calculated by applying a micromechanical differential scheme. The values of the investigated mechanical properties are shown to decrease with an increase in porosity, but the thermal expansion values are insensitive to porosity. The variation in mechanical properties as a function of porosity leads to distinct porosity dependence of thermal shock resistance for crack initiation and crack propagation for DPF grade synthetic cordierite.

Keywords: Diesel particulate filter, cordierite, porosity, microcracking, micromechanical differential scheme.

\footnotetext{
*Corresponding author. Telephone - +1(865) 241-4841; Fax - +1(865) 574-6098; Email - shyama@ornl.gov
} 


\section{Introduction}

The functional characteristics of diesel particulate filters (DPFs) are such that the porosity of the filter is a key determinant for filtration as well as mechanical properties. Cordierite (chemical formula $-\mathrm{Mg}_{2} \mathrm{Al}_{4} \mathrm{Si}_{5} \mathrm{O}_{18}$ ) is a low thermal expansion ceramic that is commonly used as a material in exhaust aftertreatment systems. The porosity needs to be optimized based on competing requirements for exhaust filtration efficiency and thermomechanical performance [1]. This is especially relevant since worldwide government regulations associated with particulate matter and $\mathrm{NO}_{\mathrm{x}}$ emissions continue to become increasingly stringent [2]. The advantages of increasing the porosity [3] of the DPF include: (i) increased loading of washcoats and possibly catalysts, such that the filter can serve in a multifunctional manner including catalytic reduction, $\mathrm{NO}_{\mathrm{x}}$ trapping, hydrocarbon oxidation in addition to trapping particulate matter, (ii) reduced engine backpressure; this leads to increased engine efficiency and (iii) increased mechanical compliance and, therefore, potential to increase resistance to thermal shock. Increasing the porosity, however, also leads to a decrease in the mechanical load-bearing ability and therefore, the disadvantages of increasing the porosity of the substrate can be summarized as follows: (i) decreased strength (and fracture toughness), (ii) decreased thermal conductivity of the substrate; both properties influence the thermal shock resistance [4-6]. A DPF with an optimal level of porosity will balance these competing effects.

DPF materials, and consequently the filters themselves, do not generally possess isotropic properties (thermal expansion, Young's modulus, etc.). Kachanov (see [7]) has shown that in the simplest case of isotropic microcracked (with penny shaped cracks) and porous materials, at least three parameters (microcrack density, porosity, and pore shape) are necessary to describe their effective properties. In general, one porosity and one microcrack density tensors are necessary to fully describe the effect of 'defects' in solids. For a porous 
and non-microcracked material, the typical empirical approach to tackle porosity effects on properties is to apply the pore shape factor, $m[8,9]$. This approach has its origin in the application of a micromechanical modified differential scheme $[10,11]$. For porous and microcracked materials, such as ceramics for DPF applications, Bruno and Kachanov [12] have shown that it is possible to apply a two-step homogenization approach, taking into account porosity and microcracks separately, since the two homogenization operations are commutative.

In this work, we investigated DPF type cordierite materials of different origin (manufacturers) and conditions (bare and coated, after service and soot loaded) with porosity in the range of $50-70 \%$, and compared their properties to those of lower porosity cordierite materials. The effects of porosity on some of the properties that determine the thermal shock resistance (for crack initiation and crack propagation $[5,13]$ ) were investigated. The properties that were measured include fracture toughness, characteristic strength, Young's modulus and coefficient of thermal expansion (CTE). Some of the available models to rationalize the above properties and the microstructural features (in particular the microcracks) linked to their variation with porosity are reviewed. It is shown that porosity and microcracking $[14,15]$ can together have a strong influence on the thermal shock resistance of cordierite DPFs. These results can aid in the identification of a DPF substrate material with optimal thermal shock resistance that is balanced with functional requirements.

\section{Materials and Experimental Procedure}

A number of materials were acquired for this investigation and their description (including porosity), and the type of characterization performed on them are summarized in Table 1. A total of 11 cordierite-based materials are included in Table 1. All materials except the bulk cordierite material (BulkCO) and low porosity cordierite (LP) were acquired 
in honeycomb forms from as-fabricated DPF devices (Fig. 1(a)). The honeycomb structures had square channels ( 1.5-2.5 $\mathrm{mm}$ size) and specimens for evaluation of properties were fabricated by following a series of dry cutting and grinding procedures reported elsewhere [16]. The porosity of specimens was measured by evaluating the specimen density and comparing it to the expected bulk density $\left(2.46 \mathrm{~g} / \mathrm{cm}^{3}\right)$ of the material. It was shown that this technique led to porosity values that were similar to those calculated with two dimensional image analysis of the Duratrap CO material [16]. Table 1 suggests that the porosity of the evaluated DPF materials varied in the range $50-70 \%$. Since the low porosity cordierite material had some closed porosity, its porosity was determined by image analysis.

The specimen preparation and experimental procedure for mechanical and thermal expansion characterization has been described in detail in previous publications [15-17]. To summarize, fracture toughness testing was performed under ambient conditions on precracked double-torsion specimens with dimensions $20 \mathrm{~mm} \times 40 \mathrm{~mm} \times$ ground specimen thickness. The ground specimen thickness was $\sim 0.25-0.40 \mathrm{~mm}$ with a flatness of $0.005 \mathrm{~mm}$. The maximum load in the fast fracture test was used to calculate the fracture toughness value at room temperature [18]. The reported values are the average of five fracture toughness tests, and the error bars indicate the standard deviation. The flexural strength testing and analysis was performed on honeycomb shaped specimens ( 7 x 14 cells in cross-section) as per the ASTM standard C1674 - 11. A total of 30 specimens were analysed to compute the characteristic strength and Weibull modulus according to two parameter Weibull analysis. The Young's modulus at room and elevated temperature was determined using resonant ultrasound spectroscopy (RUS) $[15,19,20]$. Thermal expansion measurements were performed in a thermomechanical analyser (TMA - Q400 TA Instruments). For the DPF specimens, measurements were performed both parallel and perpendicular to the extrusion direction whereas only one measurement was performed for the low porosity and bulk cordierite specimens (which are assumed to be thermally isotropic). The reported average 
linear CTE values are from the second heating cycle between 20 and $1000^{\circ} \mathrm{C}$ (the thermal expansion curves are more stable in the second cycle where effects such as soot burning can influence the first cycle). Further details of the high temperature RUS and thermal expansion measurement procedure are reported elsewhere [15].

The microstructure of the porous cordierite samples was examined by field emission gun scanning electron microscopy (FEG SEM - Hitachi S4800) and by Electron Back Scattered Diffraction (EBSD). Specimens for EBSD characterization were prepared by embedding in cold-setting epoxy, polishing to a mirror finish, and then cutting the polished and embedded specimens into $\sim 8 \times 8 \times 2 \mathrm{~mm}$ sections. These sections were then polished using argon ions in a Gatan Ilion+ cross-section sample preparation tool. Final polishing used 3 $\mathrm{keV}$ argon ions. The specimen surface was lightly coated with carbon via evaporation, and conductive paint was applied to cover all other faces. EBSD was then performed in a JEOL6500F SEM, using a $15 \mathrm{keV}, \sim 6 \mathrm{nA}$ beam. The near-match of $\{010\}$ and $\{001\}$ lattice parameters resulted in "checkerboard" pseudosymmetry of cordierite crystals oriented along those axes.

\section{Microstructure of porous cordierite for diesel}

\section{particulate filters}

The macro- and microstructure of porous DuratrapCO ${ }^{\circledR}$ cordierite for DPF applications is included in Fig. 1. The other DPF cordierite materials have qualitative features similar to the ones described in this section. Fig. 1(a) is an image of a $2 \times 2$ cell section of this material that shows the square channels with $2.25 \mathrm{~mm}$ sides. A low magnification SEM image showing the 50\% porous microstructure is shown in Fig. 1(b). The higher magnification in Fig. 1(c) reveals the grain structure and the presence of microcracks. It is noted that some microcracks begin and terminate on the pores. The grains of cordierite are elongated along the c-axis of the crystal as described previously (and 
indicated in Fig. 1(c)) $[14,15]$. The microcracks may be preferentially aligned parallel to the long axis of grains within collections of neighboring grains with similar orientation termed 'domains' [14, 15, 21]. The presence of domains is shown in the EBSD image in Fig. 1 (d) where the colors denote that several grains (separated by dark grain boundaries) have similar orientation. The microcracks in porous cordierite form at the domain level since the thermal mismatch stresses are generated at this microstructural scale. Finally, it is noted that the extrusion direction is within the image plane of Figs. 1(b) and (c), whereas, it is perpendicular to the image plane in Figs 1(a) and (d). In Fig. 1(d), the grains, therefore, appear equiaxed but they appear elongated in Fig. 1(c). Since the crystallographic c-axis is the lowest thermal expansion direction [15], the overall thermal expansion is lower in the extrusion direction.

\section{Mechanical and thermal property variations with porosity}

\subsection{Fracture toughness and strength}

Fig. 2 indicates that the fracture toughness of porous cordierite specimens can change by a factor of over 20 in the investigated porosity range of $0-70 \%$. For the cordierite DPF specimens (with porosity 50-70\%), Fig. 2 shows that the double-torsion fracture toughness $\left(K_{I C}\right)$ decreased by a factor of four $(0.4$ to $0.1 \mathrm{MPa} \sqrt{\mathrm{m}})$ as porosity of the cordierite specimens increased. The following observations are made on the results in Fig. 2:

- The fracture toughness values of the cordierite specimens are most sensitive to the porosity of the specimen. Other factors, such as having a catalytic washcoating, service life or additional aging (Table 1), do not lead to a noticeable trend in fracture toughness (for example, the power-law fit exponents remain 3.0 versus 3.1 for coated and bare DPF cordierite specimens, respectively). 
- The fracture toughness of bulk cordierite with zero porosity is $2.31 \pm 0.13 \mathrm{MPa} \sqrt{\mathrm{m}}$. This toughness value is along the lines of values reported for bulk cordierite and other silicate ceramics, which vary between 2-3 MPa $\sqrt{\mathrm{m}}$ (even in the cases where the material is nonstoichiometric [22-26]).

The characteristic strength $\left(\sigma_{f}\right)$ and Weibull modulus of honeycomb specimens are reported as a function of porosity in Fig. 3. The characteristic strength $\left(\sigma_{f}\right)$ decreases with increasing porosity, but has a weaker dependence on porosity compared to fracture toughness. It is noted that the strength value will be sensitive to the employed specimen machining procedure. The Weibull modulus does not have a clear dependence on porosity and remains nearly constant (Fig. 3). We can state based on results presented in Figs. 2 and 3 that that the dependence of fracture toughness and strength on porosity is different, with the former having a stronger dependence.

\subsection{Elastic modulus}

The Young's moduli of all specimens listed in Table 1 were measured at room temperature. As indicated in Table 1, some bare and coated materials were chosen from the sample set for high-temperature RUS investigations, together with bulk ( zero porosity) and low porosity cordierite materials. Results of the high temperature RUS measurements are reported in Fig. 4. In all materials, some hysteresis (upon heating and cooling) in the Young's modulus values was observed. This is due to the well-known phenomenon of microcrack healing upon heating, and successive delayed microcrack opening upon cooling (the mentioned phenomena are discussed in detail in [27-29], and have also been observed for thermal expansion study in cordierite and other microcracked ceramics [30-32]). Evidence for microcrack healing at elevated temperature was recently reported for the Duratrap CO material [15]. 
It is noted that coated DPF cordierite (C-1, B-1 and B-2) materials have identical initial and final (after the heating-cooling cycle) Young's moduli, while in bare DPF cordierite materials (C-0 and B-0) the final Young's modulus is lower. This observation suggests that the catalytic coating can penetrate microcracks, and therefore suppress further (stable) microcrack propagation upon cooling. The temperature dependence of Young's modulus for the bare and coated cordierite DPF materials is also different with the coated specimens showing a smoother increase in Young's modulus with increasing temperature. The Young's modulus of the bulk cordierite upon cooling is higher than that upon heating. This is due to presence of residual glass in the bulk cordierite material; some of the glass devitrifies during the heating cycle, leading to an increase in modulus. The remnant glass softening in bulk cordierite was evidenced by broad peaks (at $>600^{\circ} \mathrm{C}$ ) in the RUS spectra that could not be analysed to determine the Young's modulus.

Fig. 5 shows that the initial Young's modulus $(E)$ also decreases with porosity in a non-linear fashion. It is important to bear in mind that the initial Young's moduli plotted in Fig. 5 contain the effect of porosity and microcracking superimposed. In order to rationalize the sole dependence of Young's modulus on porosity, we would need to have an estimate of the microcrack density $(\rho)$. The microcrack density estimation for the specimens is performed in the discussion section.

\subsection{Fracture surface energy}

The fracture energy, $\gamma$, can be approximated to the strain energy release rate $G$, which can be evaluated by applying Griffith's equation $G_{I C}=K_{I C}{ }^{2} / E$ to the above reported data. Fig. 6 shows that $G$ also decreases with porosity. It is noted that the fracture energy has stronger dependence on porosity compared to fracture toughness. In the investigated porosity range of $0-70 \%$, the fracture energy varied by a factor of 30 . 


\subsection{Thermal expansion}

Available models do not predict any dependence of the thermal expansion on porosity (see $[33,34]$ for two recent reviews on the subject). Since the material is interconnected, no obvious physical effect of porosity would influence free expansion under temperature change. The difference here, however, may be associated with different microcrack densities. Microcracking that results from lattice thermal expansion anisotropy strongly influences the thermal expansion. This has been shown for a number of systems including aluminium titanate $[35,36], \beta$-eucryptite $[30]$, and cordierite $[14,15,37])$ ). Fig. 7 shows that the linear thermal expansion (dilation in percentage, defined as $100 * \Delta l / l_{0}, l_{0}$ initial sample length) of some of the investigated samples from room temperature to $1000^{\circ} \mathrm{C}$.

The low-porosity cordierite material has a higher thermal expansion than the bulk cordierite. This can be explained with the presence of second phases and crystal chemistry: indeed, the reversible transitions around 200 and $600^{\circ} \mathrm{C}$ indicate the presence of silica (cristobalite and quartz, respectively) in low-porosity cordierite. The silica transformations can be an additional source of microcracking in low-porosity cordierite. In Fig. 7a, the bulk cordierite material has some temperature hysteresis due to devitrification of the remnant glass. The lattice expansion is strongly influenced by the crystal chemistry [38-40], but this discussion is outside the scope of the present manuscript. It is noted that in all materials, the second cycle has less hysteresis than the first. This phenomenon is more evident for sootloaded filters, where the soot is oxidized within the first heating cycle.

The linear coefficient of thermal expansion from RT to $1000^{\circ} \mathrm{C}, \alpha_{\mathrm{RT}-1000^{\circ} \mathrm{C}}$, is plotted as a function of porosity in Fig. 8, where the insets show data for the DPF porous cordierites only. We notice no particular dependence on porosity, but clear dependence on the direction: the thermal expansion parallel (i.e., along) the extrusion direction is generally half that of the 
perpendicular (i.e., transverse) direction. This observation is related to the crystallographic texture of the solid material $[41,42]$ as noted in Section 3.

\section{Discussion}

It is noted that the dependence of mechanical properties and thermal expansion of cordierite is a function of porosity and microcracking. The microcrack density, in turn is related to several parameters like glass content, domain size, anisotropic lattice CTEs and crystal chemistry. These parameters are not characterized for the cordierite materials investigated. We used commercial products in our investigation, which naturally provided constraints such that we could not vary porosity and microcrack density in the materials independently. In spite of this limitation, it is demonstrated in this section that several trends can be identified by use of the porosity microstructural parameter alone. We begin by presenting a methodology to estimate the microcrack density from the temperature dependence of Young's modulus.

\subsection{Estimation of Microstructural Parameters}

As mentioned before, all measured data reflect the effect of two parameters, porosity and microcracking, on the material properties. Measurement of microcracking density remains an experimental challenge. For Young's modulus, it is possible to deconvolute the effect of the two parameters by utilizing the high-temperature RUS measurements (Fig. 4). This deconvolution is performed using a procedure that is illustrated in Fig. 9 (see [28]).

If the dependence of the Young's modulus on temperature is known up to a certain $T_{\max }$ (in our case $1000^{\circ} \mathrm{C}$ ), we can assume that at $\mathrm{T}_{\max }$ all (or most) of the microcracks are healed. This assumption is certainly reductive for strongly anisotropic materials such as aluminium titanate (see [33, 43]), but it is reasonable for cordierite [37, 44]. In Reference [44], it is demonstrated that the thermal stresses saturate above $800^{\circ} \mathrm{C}$, but it is also estimated that $\mathrm{T}_{\max }$ 
should lie above $1000^{\circ} \mathrm{C}$ for porous cordierite. The value of the Young's modulus at $\mathrm{T}_{\max }$ can be considered as that of the porous, microcrack-free, material at that temperature. Back extrapolation to room temperature (RT) will therefore yield the Young's modulus of the porous, non-microcracked material $\left(E_{0 m}\right)$. This extrapolation has been suggested in [14] as being linear:

$$
E_{0 \mathrm{~m}}=E_{\mathrm{T} \max } /\left(1-15 \times 10^{-5} \times \Delta \mathrm{T}\right)
$$

Where $\Delta \mathrm{T}=\mathrm{T}_{\max }-\mathrm{RT}$, and the coefficient $15 \times 10^{-5}$ is an estimate made on the basis of the temperature dependence for oxide ceramics reported elsewhere [45].

On the basis of this estimation, the non-microcracked Young's modulus can be plotted as a function of porosity as in Fig. 10. To these data, we can fit a power law of the kind [8,9]:

$$
E_{0 \mathrm{~m}} / E_{0}=(1-p)^{m}
$$

where, $E_{0}$ is the value of the Young's modulus of the dense cordierite (zero porosity and no microcracks). Toohill et al. [46] report a value $E_{0}=142.2 \mathrm{GPa}$ (and $v_{0}=0.31$ ). The fit of the present data (power law type general non-linear fit) gives a value of $E_{0}=125.7 \mathrm{GPa}$, and allows us to determine the pore morphology factor $m=2.6$. The estimation of the $m$ value seems reasonable, since values obtained on the basis of tomography data and FEM (finite element modeling) simulation $[28,47]$ are reported to be $m=2.7$.

With the use of the differential scheme approximation (DS, see [7, 11]), we can estimate the microcrack density parameter, $\quad=\frac{1}{V} \times \sum_{k} a_{k}^{3}$ (where $\mathrm{V}$ is the volume under investigation, otherwise called the representative volume element RVE, and the microcracks are considered penny-shaped with radius $a_{k}$ ). This can be done by means of the equation [12]

$$
\frac{E_{0 m}}{E_{f i n}}=e^{C_{2} \rho}
$$

Where the constant $C_{2}$ is given by

$$
C_{2}=\frac{16 \cdot\left(1-v^{2}\right) \cdot(10-3 v)}{45 \cdot(2-v)}
$$


$C_{2}$ depends only on the Poisson's ratio, which for porous materials (with spherical pores, and porosity $p$ ) can be calculated as a function of the bulk Poisson's ratio $v_{0}$ using the relation [48]

$$
v=v_{0}+\left(0.2-v_{0}\right) p
$$

Equation 3 makes use of the information on the fully porous and microcracked material (the value measured at the end of the temperature cycle, $E_{f i n}$ in Fig. 9, is taken, to avoid influence of previous sample history), and on the porous material free of microcracks $\left(E_{0 m}\right)$. Table 2 summarizes the microstructural parameters $m$ and $\rho$ as a function of porosity for bare and coated filter materials for which high temperature Young's modulus measurements were performed. The microcrack density values for porous cordierite materials found here are in the range of 0.3-0.5 and agree well with values found in prior work [49] using uniaxial (compression) testing.

\subsection{Effect of microstructural parameters on Young's modulus, strength and fracture toughness}

The power-law type porosity dependence of room temperature Young's modulus, strength, fracture toughness and fracture energy are summarized for the analyzed cordierite materials in Table 3. In making the fitting parameter calculations in Table 3, no discrimination is made between bare and coated specimens.

The minimum solid area model predicts the same porosity dependence of Young's modulus, strength and fracture toughness [50]. Experimental results describing the $E-p, \sigma_{f}-p$ and $K_{I C}-p$ relationship for various materials systems show considerable scatter in the data. Tancret et al. [51] found a similar exponent for the porosity dependence of $E$ and $K_{I C}$ in YBCO superconducting ceramics. These authors adjusted the dependence of $E$ and $K_{\mathrm{IC}}$ on 
porosity by including a micro-(closed) porosity term, as suggested by Jernot et al. [52].

Atkinson et al. [53] found a linear correlation between $E$ and $\sigma_{f}$ in porous magnesia-spinel composites, but a non-linear one between $G$ and $E$. A recent report by Meille et al. [54] on porous alumina ceramics demonstrated (using compressive strength) a similar $\sigma_{f} v s . p$ dependence (linear) as the data presented in this work. Meille et al. state, however, that the compression loading failure mode transitions from brittle to cellular with increasing porosity.

Table 3 indicates that when the entire investigated porosity range $(0-70 \%)$ is considered, the power-law exponents for the porosity dependence of Young's modulus, fracture toughness and fracture energy are similar (2.3, 2.7 and 3.0, respectively). This result is broadly consistent with the available models and experimental data in some systems as discussed above. If the DPF cordierite materials (with porosity $50-70 \%$ ) are considered separately, the porosity dependence of strength and Young's modulus are similar but the fracture properties have a stronger dependence on porosity. The power-law exponent value for fracture toughness for DPF cordierite materials (with porosity $50-70 \%$ ) is 3.1 which is twice the power-law exponent for strength (1.6) and Young's modulus (1.7). For the remainder of the manuscript, the porosity dependence of properties of the DPF cordierite materials (with 50-70\% porosity) will be discussed due to the following reasons: (a) the thermal shock resistance of the DPF cordierite materials is important in the technical application, (b) strength testing was performed solely for the DPF cordierite materials, (c) the majority of our available data (except two data points for bulk and low porosity cordierite) are for the DPF cordierites, and (d) in the $50-70 \%$ porosity range, the fracture properties have a stronger porosity dependence compared to strength and Young's modulus as noted above.

Rice's analysis of the available data in the literature [50] demonstrated similar $E-p$, $\sigma_{\mathrm{f}}-p$ and $K_{I C}-p$ dependence for the case of simple, elastic crack propagation. Rice [50, 55], however, also catalogued a number of other cases and examples where the fracture toughness can have a stronger dependence on porosity compared to strength or Young's modulus 
dependence on porosity, as is the case for the various DPF cordierite materials considered. A brief review of the literature suggests the following reasons for differences in the fracture toughness and Young's modulus dependence in porosity for the DPF grade cordierite materials:

- Interactions such as crack branching, bridging, and coalescence are more likely at larger crack sizes (as is the case in long cracks in double-torsion test specimens for fracture toughness measurements) and such interactions are promoted by the preexisting microcracks $[55,56]$.

- Non-linearity in the stress-strain response at higher strains due to mechanically induced microcracks interacting with thermally induced microcracks by crack propagation and linkage $[57,58]$. The non-linearity leads to a deviation from the linear elastic deformation that all the discussed models for $K_{I C}-p, \sigma-p$ and $E-p$ are predicated upon. In this regard, it is noted that the static and dynamic Young's modulus of specimens with microcracks can be significantly different [58-61]. The RUS technique employed in this investigation is a dynamic technique. As such, it may be surmised that the static modulus dependence with porosity will be closer to that of fracture toughness dependence of porosity.

- As models suggest, the pre-existing microcracks can only contribute to a decrease in the fracture toughness $[62,63]$ so higher deviations of $K_{I C}-p$ from $E-p$ can only be due to porosity and microcracks acting in concert to further degrade the toughness.

To the best of our knowledge, there are no studies of material behavior where porosity and micocracking are both systematically changed. The results of the present investigation indicate that porosity and microcracking together can cause a larger decrease in the fracture toughness of the material than the decrease due to porosity alone. The different dependence of fracture toughness and strength on the porosity has implications for crack initiation and 
propagation in the context of thermal shock resistance of the materials as shown in the next section.

\subsection{Thermal shock resistance of DPF cordierite materials}

All the above measured quantities can be used to evaluate the most relevant thermomechanical characteristic of DPF materials, the thermal shock resistance. Researchers have measured the effect of microcracking on the thermal shock resistance[64]. According to Hasselman (and other pioneering studies [5, 6, 13]), a distinction needs to be made between resistance to thermal shock for crack propagation and crack initiation. The thermal shock resistance to crack propagation is defined by the parameter $R_{s t}$

$$
R_{s t}=\left(\gamma / \alpha^{2} E\right)^{1 / 2}
$$

where $\gamma$ is the surface energy. Maximizing $R_{s t}$ would give a material with higher resistance to crack propagation under thermal shock conditions. If we assume stable crack growth, $\gamma \sim G=$ $K_{I C}{ }^{2} / E$, the crack propagation criterion reduces to

$$
R_{s t}=\left(K_{I C}^{2} / \alpha^{2} E^{2}\right)^{1 / 2}=K_{I C} / \alpha E
$$

The thermal shock parameter for crack initiation is defined by

$$
R=\sigma_{f} / \alpha E
$$

Maximizing $R$ would give a material with higher resistance to crack initiation under thermal shock conditions. In both Equations 7 and 8, we have ignored the dependence on Poisson's ratio (typically of the kind $1-v$ ) and thermal conductivity. A plot of the thermal shock parameters $R$ and $R_{s t}$ in arbitrary units (a.u.) as a function of porosity is shown in Fig.11.

Fig. 11 shows that the axial (or parallel to extrusion axis) thermal shock resistance is always higher than the corresponding value in the transverse (or perpendicular to extrusion axis) direction. This is expected and corresponds to engineering design requirement against macrocracks that most frequently form perpendicular to the extrusion axis. It is also noted 
that while crack propagation depends on porosity, crack initiation has a weak correlation to porosity. Therefore, on the basis of the present analysis, it can be stated that the engineering design criteria would not coincide for crack initiation and propagation, and optimizing one would not impact the other to the same extent.

The discussion in Section 5.2 about similar porosity dependence of strength and Young's modulus of DPF cordierite materials can be used to explain the weak porosity dependence of crack initiation thermal shock resistance. The porosity effects on strength and modulus cancel each other according to Equation 8. The porosity dependence of crack propagation thermal shock resistance, however, is related to the much stronger fracture toughness dependence of porosity, compared to Young's modulus (Equation 7). The presence of thermally induced microcracks and their interaction with the macrocrack and subsequent formation of mechanically induced microcracks are key factors in the crack propagation induced thermal shock resistance decrease of DPF cordierite at higher porosity. These results can help in the design of DPF materials with optimum level of porosity such that the thermal shock resistance is balanced with filtration characteristics of the device.

\section{Conclusions}

The porosity dependence of several thermal and mechanical properties (Young's modulus, fracture toughness, strength, CTE) has been presented for cordierite. The influence of microcracking and pore morphology on the mechanical properties has also been taken into account.

The salient conclusions of this investigation are the following:

- The room temperature mechanical properties (characteristic strength, fracture toughness, Young's modulus) of cordierite are most sensitive to the porosity of the specimen. Other factors such as catalytic washcoating, service life, additional aging or soot loading do not have a pronounced influence on these properties. 
- Increasing porosity led to a decrease in all investigated mechanical properties but did not affect the thermal expansion of porous cordierite. This result is broadly consistent with available theoretical models and predictions. Pore morphology and microcrack density effects however, needed to be deconvoluted from porosity effects. A simple calculation procedure was suggested to this end using the Young's modulus variation with temperature.

- The determination of the non-microcracked Young's modulus (of selected materials) allowed the estimation of the microcrack density and the pore morphology factor $(m)$. We have found that $m \sim 2.6$; with an alternative approach, we have determined $m$ to lie between 2.2 and 2.9 for the investigated DPF materials and microcrack density to lie between 0.3 and 0.5 and both are in good agreement with independent literature data.

- When all data in a porosity range of $0-70 \%$ are considered, the Young's modulus, fracture toughness and fracture energy had similar dependence on porosity as predicted by simple analytical models. For the DPF cordierite materials, the porosity dependence of the fracture properties was stronger compared to the porosity dependence of Young's modulus and strength. The greater porosity dependence of fracture properties was explained on the basis of crack size effects (larger cracks for fracture toughness measurement) and the expected non-linearity in the tensile response of the DPF cordierite materials at higher loads.

- The thermal shock resistance parameters $R_{s t}$ and $R$ were calculated on the basis of the measured data. Resistance to crack initiation (i.e., $R$ ) was independent of porosity, while resistance to crack propagation (i.e., $R_{s t}$ ) decreased with porosity. The difference in porosity dependence of the thermal shock initiation and propagation resistance is due to the difference in porosity dependence of fracture toughness, strength and Young's modulus. 


\section{Acknowledgments}

Research sponsored by the U.S. Department of Energy, Assistant Secretary for Energy

Efficiency and Renewable Energy, Office of Vehicle Technologies, as part of the Propulsion

Materials Program. We thank Rick Lowden (ORNL) and Allen Haynes (ORNL) for

reviewing the manuscript.

\section{References}

[1] Cutler WA. Overview of Ceramic Materials for Diesel Particulate Filter Applications. In: 28th International Conference on Advanced Ceramics and Composites A: Ceramic Engineering and Science Proceedings. John Wiley \& Sons, Inc., USA, 2008. p.421-30.

[2] Konstandopoulos AG, Kostoglou M, Vlachos N, Kladopoulou E. Advances in the science and technology of diesel particulate filter simulation. In: Guy BM, editor. Advances in Chemical Engineering, vol. 33. Academic Press, 2007. p.213-94.

[3] Merkel GA, Tao T. Cordierite filters with reduced pressure drop. European Patent EP1639236 A4, 2009.

[4] Hasselman DPH. Elastic Energy at Fracture and Surface Energy as Design Criteria for Thermal Shock. J Am Ceram Soc 1963;46:535-40.

[5] Hasselman DPH. Unified Theory of Thermal Shock Fracture Initiation and Crack Propagation in Brittle Ceramics. J Am Ceram Soc 1969;52:600-4.

[6] Kingery WD. Factors Affecting Thermal Stress Resistance of Ceramic Materials. J Am Ceram Soc 1955;38:3-15.

[7] Kachanov M. Effective elastic properties of cracked solids: critical review of some basic concepts. Appl Mech Rev 1992;45:304-35.

[8] Bruno G, Efremov AM, Levandovskyi AN, Clausen B. Connecting the macro- and microstrain responses in technical porous ceramics: modeling and experimental validations. $\mathrm{J}$ Mater Sci 2011;46:161-73.

[9] Gibson LJ, Ashby MF. The Mechanics of Three-Dimensional Cellular Materials. Proc Roy Soc London A 1982;382:43-59.

[10] McLaughlin R. A study of the differential scheme for composite materials. Int J Eng Sci 1977;15:237-44.

[11] Vavakin A, Salganik R. Effective characteristics of nonhomogeneous media with isolated inhomogeneities. Mech Sol 1975;10:58-66.

[12] Bruno G, Kachanov M. Porous microcracked ceramics under compression:

Micromechanical model of non-linear behavior. J Eur Ceram Soc 2013;33:2073-85.

[13] Hasselman D. Thermal stress resistance parameters for brittle refractory ceramics: a compendium. Am Ceram Soc Bull 1970;49:1033-7.

[14] Bruno G, Efremov A, An C, Wheaton B, Hughes D. Connecting the macro and microstrain responses in technical porous ceramics. Part II: microcracking. J Mater Sci 2012;47:3674-89.

[15] Shyam A, Lara-Curzio E, Pandey A, Watkins TR, More KL. The Thermal Expansion, Elastic and Fracture Properties of Porous Cordierite at Elevated Temperatures. J Am Ceram

Soc 2012;95:1682-91. 
[16] Shyam A, Lara-Curzio E, Watkins TR, Parten RJ. Mechanical Characterization of Diesel Particulate Filter Substrates. J Am Ceram Soc 2008;91:1995-2001.

[17] Gordon T, Shyam A, Lara-Curzio E. The Relationship Between Microstructure and Fracture Toughness for Fibrous Materials for Diesel Particulate Filters. J Am Ceram Soc 2010;93:1120-6.

[18] Shyam A, Lara-Curzio E. The double-torsion testing technique for determination of fracture toughness and slow crack growth behavior of materials: A review. J Mater Sci 2006;41:4093-104.

[19] Migliori A, Sarrao JL, Visscher WM, Bell TM, Lei M, Fisk Z, Leisure RG. Resonant ultrasound spectroscopic techniques for measurement of the elastic moduli of solids. Physica B 1993;183:1-24.

[20] Tan Y, Shyam A, Choi WB, Lara-Curzio E, Sampath S. Anisotropic elastic properties of thermal spray coatings determined via resonant ultrasound spectroscopy. Acta Mater 2010;58:5305-15.

[21] Harada T, Hamanaka T, Hamaguchi K, Asami S. Cordierite honeycomb-structural body and a method for producing the same. US Patent 4869944 A, 1989.

[22] Fantozzi G, Orange G, Liang K, Gautier M, Duraud J-P, Maire P, Le Gressus C, Gillet E. Effect of Nonstoichiometry on Fracture Toughness and Hardness of Yttrium Oxide Ceramics. J Am Ceram Soc 1989;72:1562-3.

[23] Gogotsi GA. Fracture toughness of ceramics and ceramic composites. Ceram Int 2003;29:777-84.

[24] Gogotsi GA, Zavada VP, Kharitonov FY. Strength and crack resistance of ceramics. Report No. 1. Cordierite. Strength Mater 1984;16:1651-55.

[25] Green DJ. An introduction to the mechanical properties of ceramics. Cambridge, UK: Cambridge University Press, 1998.

[26] Oliveira FAC, Fernandes JC, Schmitt J, Rosa LG, Dias D. Fracture Toughness of Dense Cordierite: Sintering Cycle Effect. Mater Sci Forum, 2013:730-732:445-9.

[27] Bruno G, Efremov AM, An C, Nickerson S. Not all microcracks are born equal: thermal vs. mechanical microcracking in porous ceramics. Advances in Bioceramics and Porous Ceramics IV: Ceram Eng Sci Proc 2011;548:137-52.

[28] Bruno G, Kachanov M. On modeling of microstresses and microcracking generated by cooling of polycrystalline porous ceramics. J Eur Ceram Soc 2013;33:1995-2005.

[29] Bruno G, Efremov AM, Clausen B, Hughes DJ, Levandovskiy AN, Pozdnyakova I. Thermal and mechanical response of industrial porous ceramics. Mater Sci Forum, 2010;652:191-6.

[30] Bruno G, Garlea VO, Muth J, Efremov AM, Watkins TR, Shyam A. Microstrain temperature evolution in $\beta$-eucryptite ceramics: Measurement and model. Acta Mater 2012;60:4982-96.

[31] Buessem W. Internal ruptures and recombinations in anisotropic ceramic materials. from. In Kriegel WW, Palmour III H, editors, Mechanical Properties of Engineering Ceramics, Interscience Publishers, New York; 1961.

[32] Thomas H, Stevens R. Aluminium titanate: a literature review. I: Microcracking phenomena. Brit Ceram Trans J 1989;88:144-51.

[33] Efremov AM, Bruno G. Modeling the impact of microcracking on the thermoelasticity of porous and microcracked ceramics. Phil Mag 2013;93:691-717.

[34] Sevostianov I. On the thermal expansion of composite materials and cross-property connection between thermal expansion and thermal conductivity. Mech Mater 2012;45:2033.

[35] Bruno G, Efremov A, Wheaton B, Bobrikov I, Simkin VG, Misture S. Micro- and macroscopic thermal expansion of stabilized aluminum titanate. J Eur Ceram Soc

2010;30:2555-62. 
[36] Ohya Y, Nakagawa Z. Measurement of crack volume due to thermal expansion anisotropy in aluminium titanate ceramics. J Mater Sci 1996;31:1555-9.

[37] Bruno G, Efremov AM, Clausen B, Balagurov AM, Simkin VN, Wheaton BR, Webb JE, Brown DW. On the stress-free lattice expansion of porous cordierite. Acta Mater 2010;58:1994-2003.

[38] Evans D, Fischer G, Geiger J, Martin F. Thermal expansions and chemical modifications of cordierite. J Am Ceram Soc 1980;63:629-34.

[39] Hochella MF, Brown GE. Structural Mechanisms of Anomalous Thermal Expansion of Cordierite-Beryl and Other Framework Silicates. J Am Ceram Soc 1986;69:13-8.

[40] Predecki P, Haas J, Faber J, Hitterman RL. Structural Aspects of the Lattice Thermal Expansion of Hexagonal Cordierite. J Am Ceram Soc 1987;70:175-82.

[41] Bruno G, Vogel S. Calculation of the Average Coefficient of Thermal Expansion in Oriented Cordierite Polycrystals. J Am Ceram Soc 2008;91:2646-52.

[42] Bubeck C. Direction dependent mechanical properties of extruded cordierite honeycombs. J Eur Ceram Soc 2009;29:3113-9.

[43] Bruno G, Efremov AM, Wheaton BR, Webb JE. Microcrack orientation in porous aluminum titanate. Acta Mater 2010;58:6649-55.

[44] Bruno G, Efremov AM, Brown DW. Evidence for and calculation of Micro-Strain in Porous Synthetic Cordierite. Scripta Mater 2010;63:285-8.

[45] Munro R. Analytical representations of elastic moduli data with simultaneous dependence on temperature and porosity. J Res Natl Inst Stand Technol 2004;109:497-503.

[46] Toohill K, Siegesmund S, Bass JD. Sound velocities and elasticity of cordierite and implications for deep crustal seismic anisotropy. Phys Chem Min 1999;26:333-43.

[47] Levandovskiy A, Efremov A, Schermerhorn A. Mechanical simulation of porous material structure represented by a uniform cubic mesh. In: Proceedings (CD) of the 3rd international conference on porous media and its applications in science and engineering ICPM3, June, 2010, p.20-5.

[48] Zimmerman RW. Elastic moduli of a solid containing spherical inclusions. Mech Mater 1991;12:17-24.

[49] Bruno G, Kilali Y, Efremov AM. Impact of the non-linear character of the compressive stress-strain curves on thermal and mechanical properties of porous microcracked ceramics. J Am Ceram Soc 2013;33:211-9.

[50] Rice RW. Porosity and microcrack dependence of fracture energy and toughness and related crack propagation at $22^{\circ} \mathrm{C}$. Porosity of Ceramics: Marcel Dekker; 1998.

[51] Tancret F, Desgardin G, Osterstock F. Influence of porosity on the mechanical properties of cold isostatically pressed and sintered $\mathrm{YBa} 2 \mathrm{Cu} 3 \mathrm{O} 7-\mathrm{x}$ superconductors. Phil Mag A 1997;75:505-23.

[52] Jernot JP, Coster M, Chermant JL. Model to Describe the Elastic Modulus of Sintered Materials. Phys Stat Sol a 1982;72:325-32.

[53] Atkinson A, Bastid P, Liu Q. Mechanical Properties of Magnesia-Spinel Composites. J Am Ceram Soc 2007;90:2489-96.

[54] Meille S, Lombardi M, Chevalier J, Montanaro L. Mechanical properties of porous ceramics in compression: On the transition between elastic, brittle, and cellular behavior. $\mathrm{J}$ Eur Ceram Soc 2012;32:3959-67.

[55] Rice RW. Grain size and porosity dependence of ceramic fracture energy and toughness at $22{ }^{\circ} \mathrm{C}$. J Mater Sci 1996;31:1969-83.

[56] Hollenberg GW, Walther G. The Elastic Modulus and Fracture of Boron Carbide. J Am Ceram Soc 1980;63:610-3.

[57] Pandey A, Shyam A, Liu Z, Goettler R. In-situ Young's moduli of the constitutive layers in a solid oxide fuel cell. J Power Sources 2015;273:522-9. 
[58] Pandey A, Shyam A, Watkins TR, Lara-Curzio E, Stafford RJ, Hemker KJ. The Uniaxial Tensile Response of Porous and Microcracked Ceramic Materials. J Am Ceram Soc 2014;97:899-906.

[59] Stafford RJ, Golovin KB, Dickinson A, Watkins TR, Shyam A, Lara-Curzio E. Comparison of Elastic Moduli of Porous Cordierite by Flexure and Dynamic Test Methods. In: Advances in Bioceramics and Porous Ceramics V. John Wiley \& Sons, Inc., 2012; p.197. [60] Tomaszewski $\mathrm{H}$. Influence of microstructure on the thermomechanical properties of alumina ceramics. Ceram Int 1992;18:51-55.

[61] Wereszczak A, Fox E, Lance M, Ferber M. Failure Stress and Apparent Elastic Modulus of Diesel Particulate Filter Ceramics. SAE Int J Mater Manuf 2012;5:517-27.

[62] Fu Y, Evans AG. Microcrack zone formation in single phase polycrystals. Acta Met 1982;30:1619-25.

[63] Rice RW, Freiman SW. Grain-Size Dependence of Fracture Energy in Ceramics: II, A Model for Noncubic Materials. J Am Ceram Soc 1981;64:350-4.

[64] Tancret F, Monot I, Osterstock F. Toughness and thermal shock resistance of YBa2Cu3O7-x composite superconductors containing $\mathrm{Y} 2 \mathrm{BaCuO} 5$ or Ag particles. Mater Sci Eng A 2001;298:268-83.

Table 1: Description and porosity of ceramic materials analyzed.

\begin{tabular}{|c|c|c|c|c|}
\hline Label & Description & Experiments $*$ & $\begin{array}{c}\text { Porosity } \\
(\%)\end{array}$ & $(1-p)$ \\
\hline C-0 & Duratrap CO - Bare/uncoated. & FT; S; TE; ERT; EHT & 50.5 & 0.50 \\
\hline C-1 & Duratrap CO + Coating 1 & FT; S; TE; ERT; EHT & 51.8 & 0.48 \\
\hline C-13 & $\begin{array}{c}\text { Duratrap CO - High Mileage - } \\
\text { Center of DPF (soot loaded) }\end{array}$ & FT; S; TE; ERT & 51.6 & 0.48 \\
\hline C-19 & $\begin{array}{c}\text { Duratrap CO - High Mileage - } \\
\text { Circumference of DPF (soot loaded) }\end{array}$ & FT; S; TE; ERT & 50.2 & 0.50 \\
\hline A-2 & Duratrap CO + Coating 2 + Aging 1 & FT; TE; ERT & 51.0 & 0.49 \\
\hline B-0 & C558 - Bare/uncoated. & FT; TE; ERT; EHT & 59.0 & 0.41 \\
\hline B-1 & C558 + Coating 1 & FT; S; TE; ERT; EHT & 57.0 & 0.43 \\
\hline B-2 & C558 + Coating 1 + Aging 2 & FT; TE; ERT; EHT & 54.4 & 0.46 \\
\hline H-0 & HCH- 21M ${ }^{\infty}$ Cordierite Uncoated & FT; S; TE; ERT & 68.1 & 0.32 \\
\hline BulkCO & $\begin{array}{c}\text { Bulk Cordierite with some residual } \\
\text { glass but no porosity }\end{array}$ & FT; TE; ERT; EHT & $\sim 0$ & $\sim 1$ \\
\hline LP & Low porosity cordierite & FT; TE; ERT; EHT & 17.3 & 0.83 \\
\hline
\end{tabular}

* Fracture Toughness - FT; Strength - S; Thermal Expansion - TE; Modulus Room Temp -

ERT; Modulus High Temp - EHT

${ }^{¥}$ Duratrap CO is cordierite based DPF material by Corning $\AA$.

${ }^{\S} \mathrm{C} 558$ is cordierite based DPF material by NGK®

$\infty \mathrm{HCH}-21 \mathrm{M}$ is cordierite based DPF material by Hitachi ${ }^{\circledR}$. 
Table 2. Microstructural parameters pore morphology factor $\mathrm{m}$ and microcrack density $\rho$ calculated using the procedure described in the text. Usually, Eq. 2 was used to calculate $\mathrm{m}$ and Eq. 3 to calculate $\rho$, except ${ }^{1}$, where $m$ was calculated using a linear approximation $E / E_{0}=$ $1-m \cdot p$ and the latter approximation is better for lower porosities.

\begin{tabular}{|c|c|c|c|}
\hline \multirow{4}{*}{ Bare } & $p$ & $m$ & $\rho$ \\
\hline \multirow{4}{*}{ Coated } & 0.51 & 2.86 & 0.34 \\
\cline { 2 - 4 } & 0.59 & 2.30 & 0.42 \\
\cline { 2 - 4 } & $0.17^{1}$ & 2.70 & 0.40 \\
\cline { 2 - 4 } & 0.52 & 2.50 & 0.37 \\
\cline { 2 - 4 } & 0.57 & 2.24 & 0.45 \\
\hline
\end{tabular}

Table 3. Summary of the porosity dependence of Young's modulus, strength, fracture toughness and fracture energy for the various cordierite specimens.

\begin{tabular}{|c|c|c|}
\hline $\begin{array}{c}\text { Mechanical } \\
\text { Property }\end{array}$ & \multicolumn{2}{|c|}{$Y=Y_{o}(1-p)^{n}$} \\
\hline & $n$ & $Y_{\text {o }}$ \\
\hline Porosity: 0.00 - 0.68 & 65.5 \\
\hline Young's modulus & 2.3 & 2.1 \\
\hline Fracture toughness & 2.7 & 67.4 \\
\hline Fracture energy & 3.0 & \\
\hline
\end{tabular}




\section{Figure Captions}

Fig. 1. Features associated with a typical cordierite material (Duratrap CO with approximately $50 \%$ porosity). (a) A $2 \times 2$ section of the material showing square channels, (b) The morphology of pores shown in a back scattered SEM image, (c) The microcracks can be seen in the SEM image at a higher magnification, (d) An electron back-scattered diffraction (EBSD) image showing the arrangements of smaller grains into larger domains.

Fig. 2. $K_{I C}$ dependence on porosity for a number of cordierite specimens. Datapoints are included for bare and coated specimens separately but the curve fit includes the fracture toughness value of all materials.

Fig. 3. Characteristic strength, $\sigma_{f}$, and Weibull Modulus dependence on porosity for a number of cordierite specimens.

Fig. 4. Temperature dependence of the Young's Modulus of bare (a) and coated (b) cordierite filter materials. In (a) the hollow symbols refer to the right axis.

Fig. 5. Young's modulus as a function of porosity for the investigated cordierite specimens.

Fig. 6. Fracture energy as a function of porosity for twelve different cordierite specimens.

Fig. 7. Dilation of selected cordierite samples (a) bare materials; LPC - low porosity cordierite, (b) coated materials. The hysteresis in bare and coated DPF cordierite materials is similar (note the different dilation scales).

Fig. 8. Average linear CTE dependence on porosity in directions that are (a) parallel and (b) perpendicular to the extrusion direction. The insets in (a) and (b) are for DPF materials with porosity between $50-70 \%$. Note that the y-axes in the main graphs are on logarithmic scales but the insets are not.

Fig. 9. Schematic of the procedure for the determination of a non-microcracked Young's modulus $E_{0 m}$. See the text for details and explanation of symbols. a.u. - arbitrary units.

Fig. 10. Dependence on porosity of the Young's modulus of equivalent non-microcracked materials (see text). The fitting line is a power law type general non-linear curve fit.

Fig. 11. The dependence of crack initiation and propagation thermal shock parameters on porosity. Curve fits are for crack propagation thermal shock resistance in the axial (parallel to extrusion axis) and transverse (perpendicular to extrusion axis) directions, respectively. Young's modulus is assumed to be isotropic. 
Figure 1

(a)

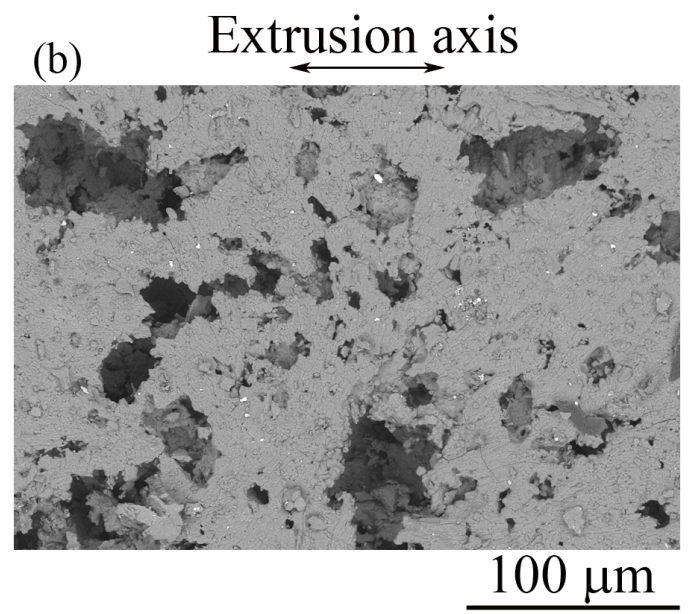

(c)

(d)
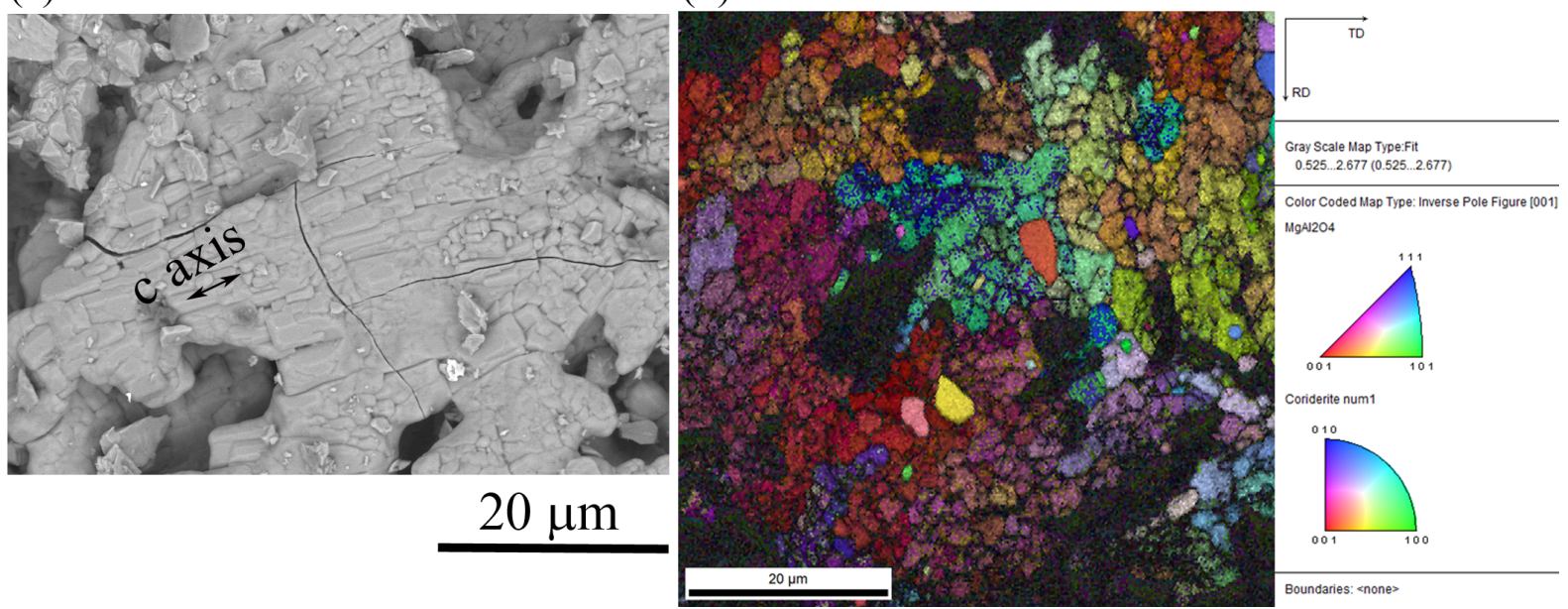

$20 \mu \mathrm{m}$ 
Figure 2

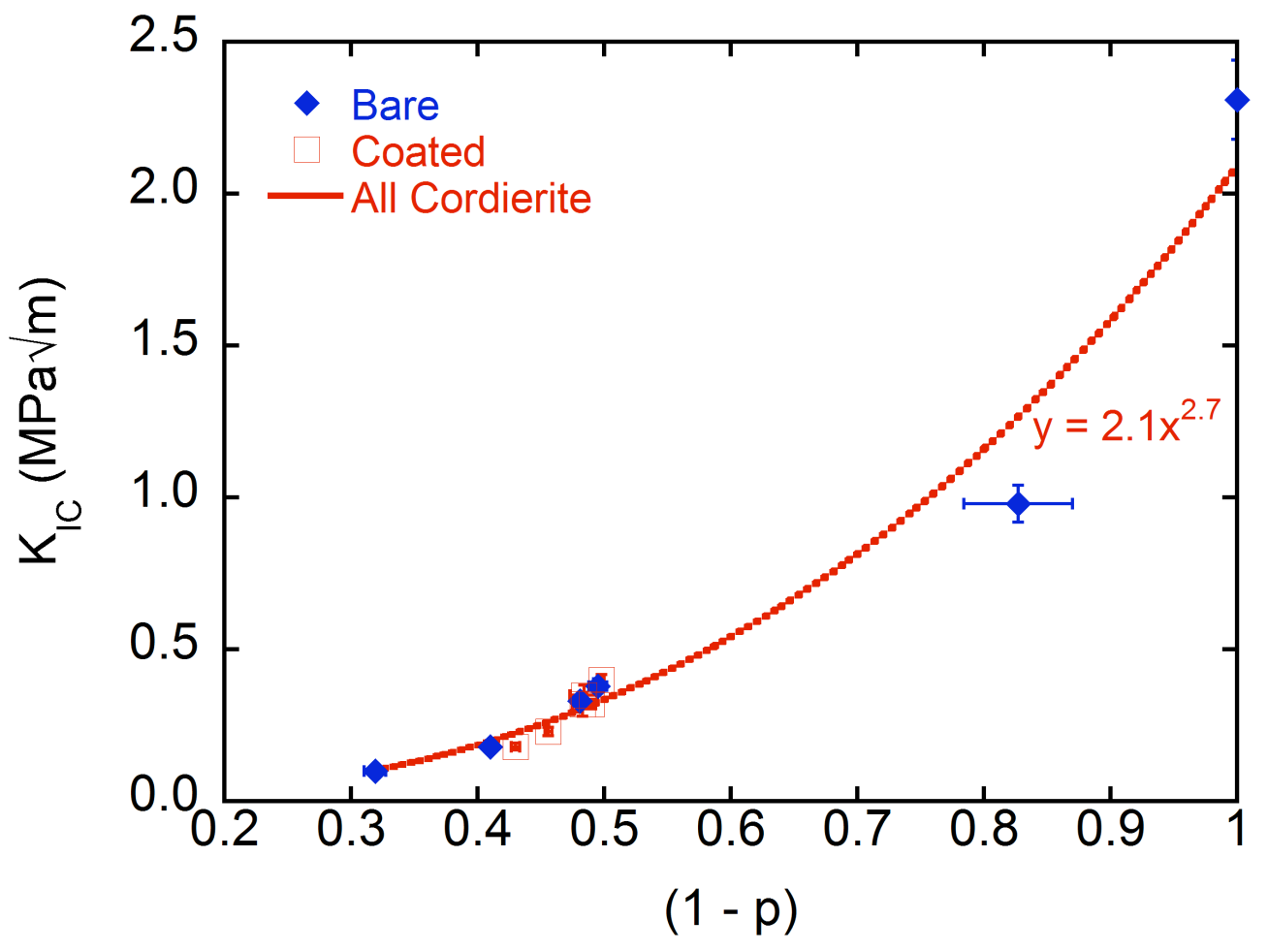


Figure 3

$\neg$ Characteristic Strength $(\mathrm{MPa}) \quad \Delta$ Weibull Modulus

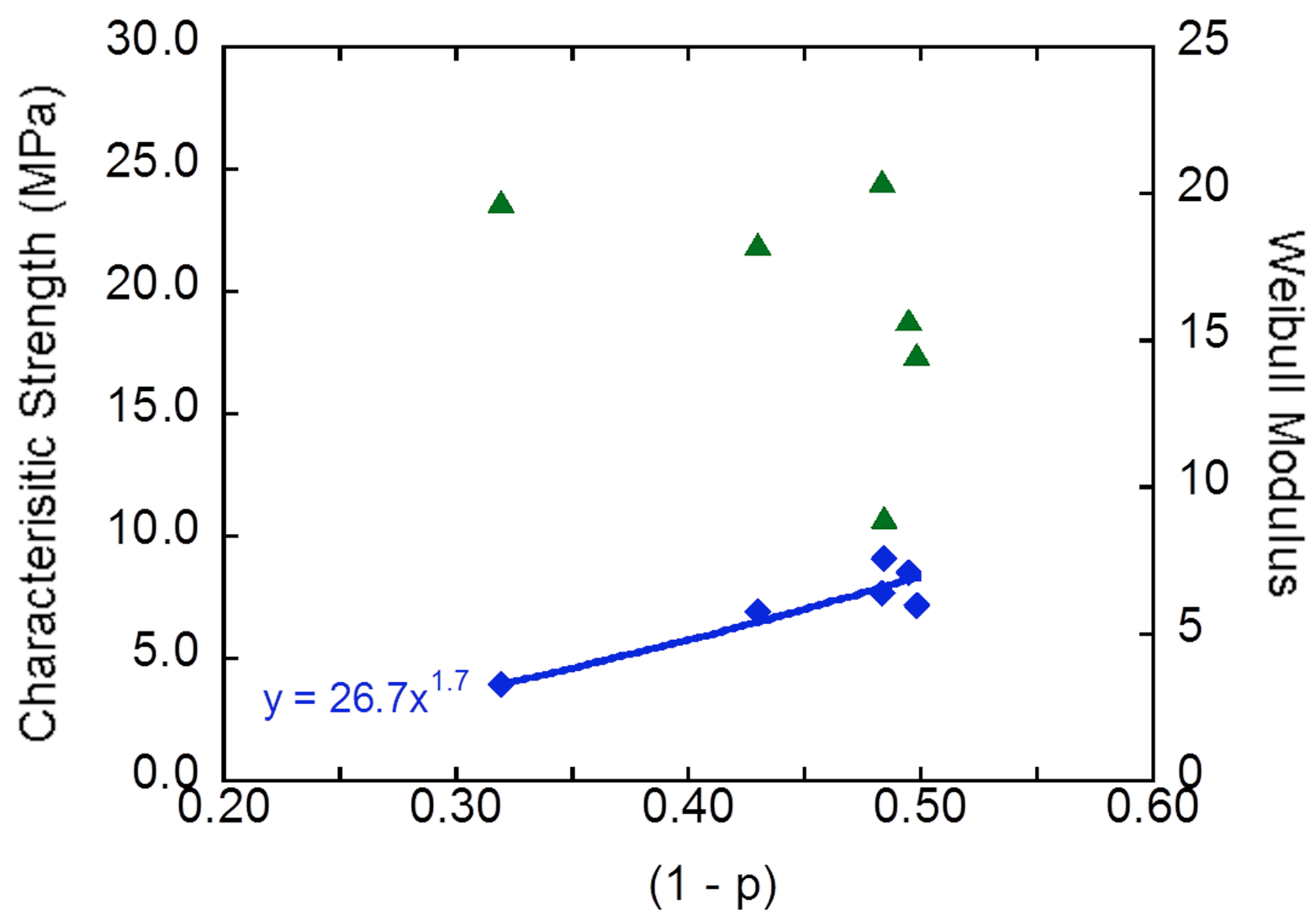




\section{Figure 4}
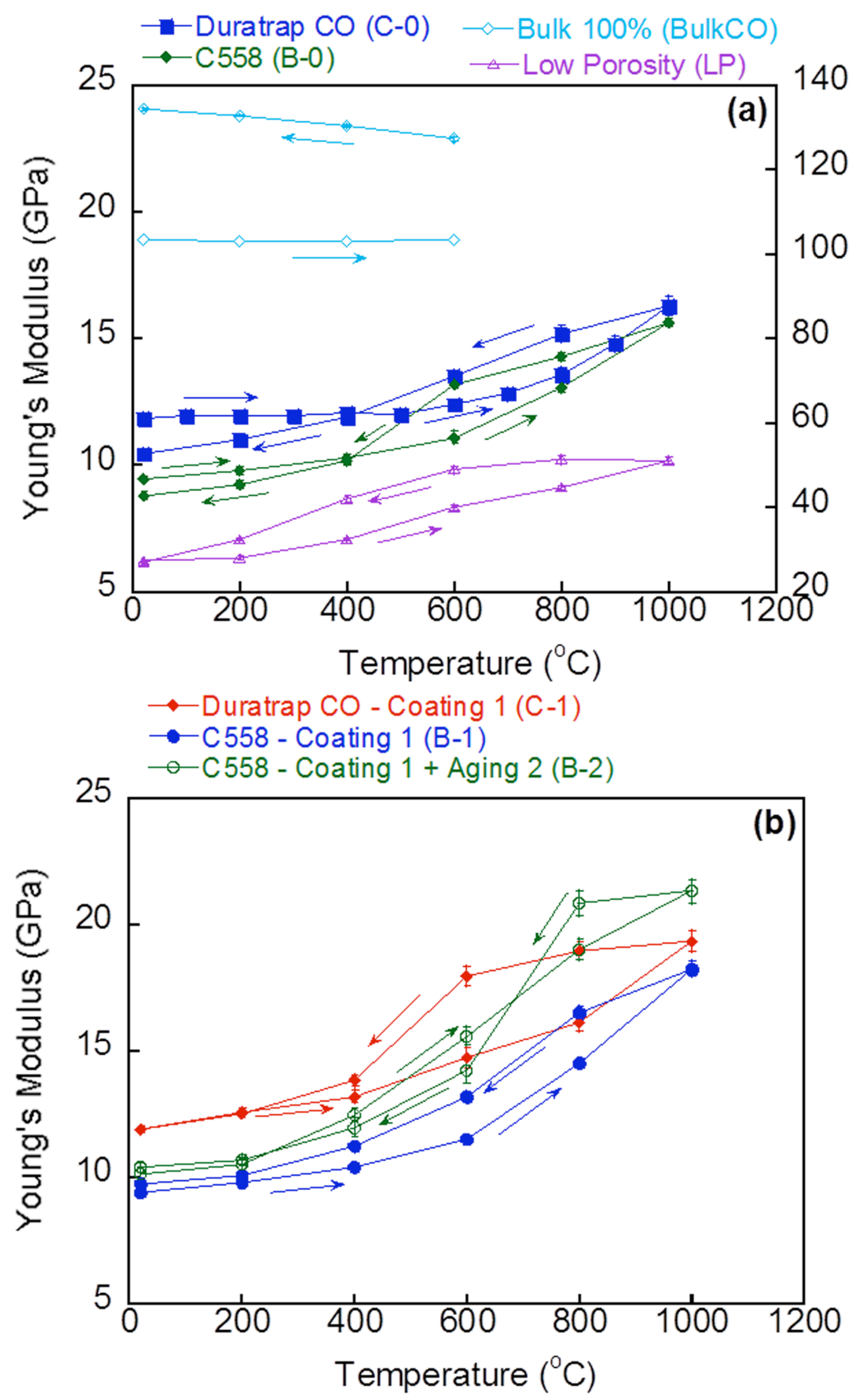
Figure 5

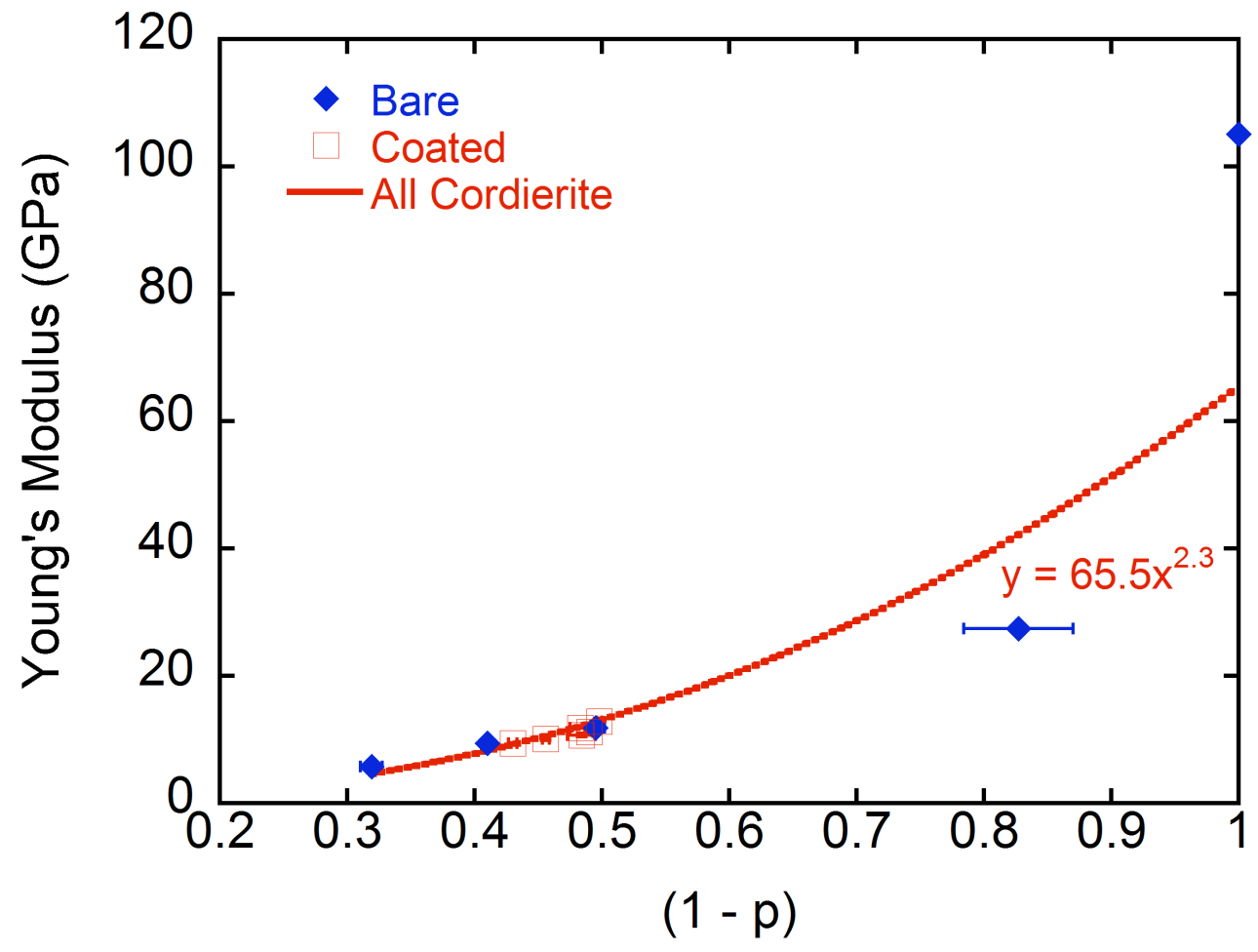


Figure 6

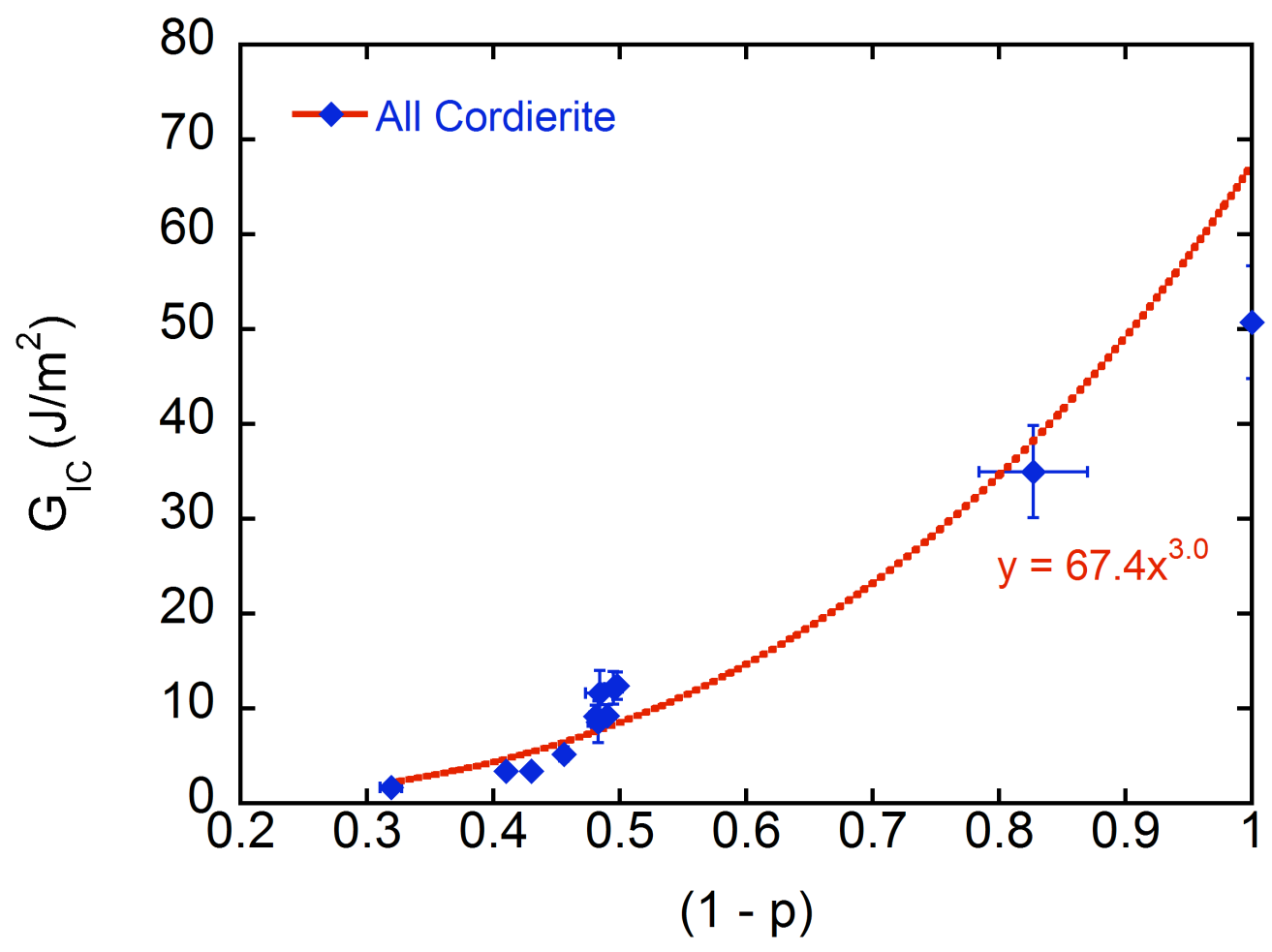




\section{Figure 7}
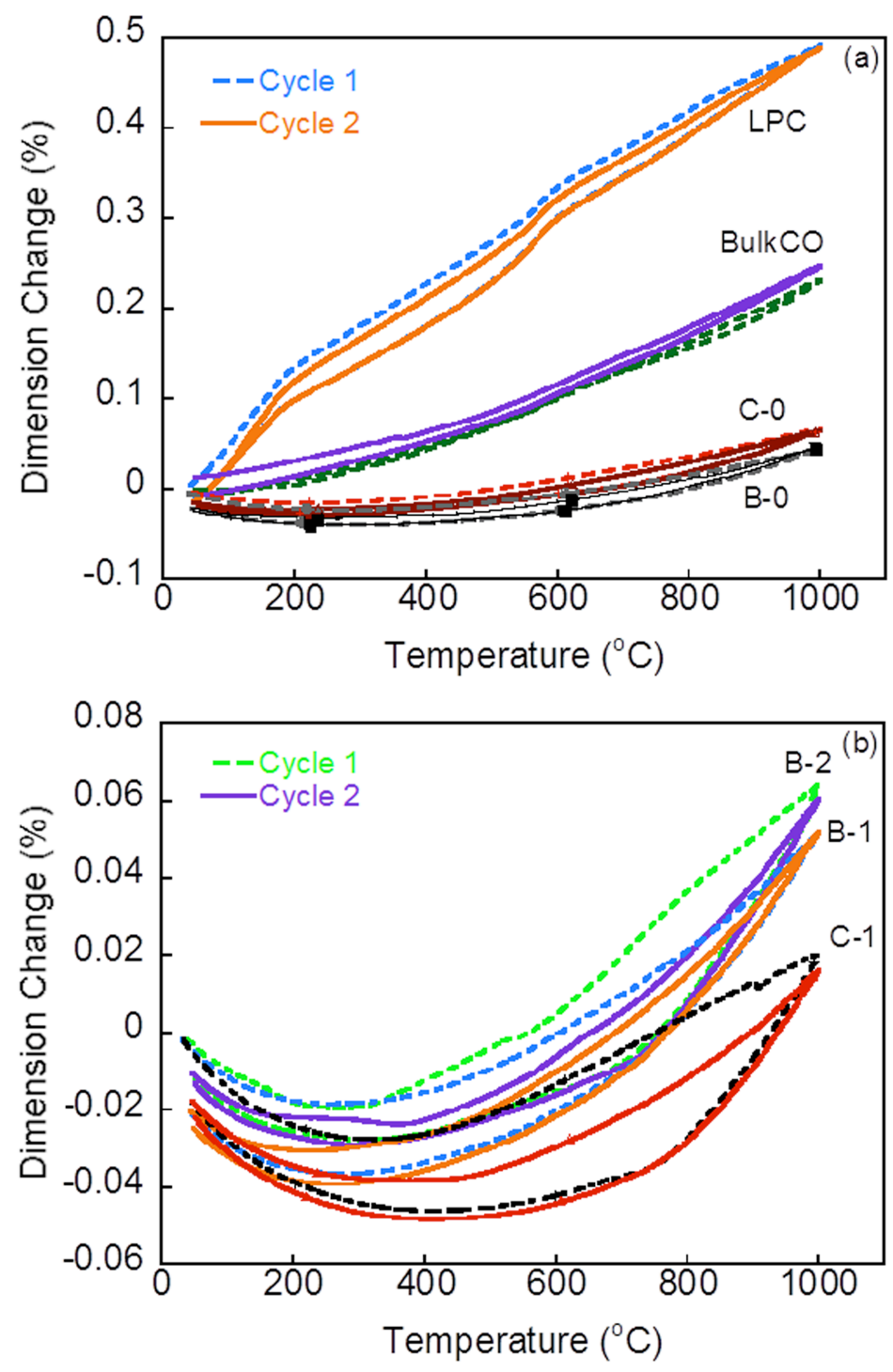


\section{Figure 8}
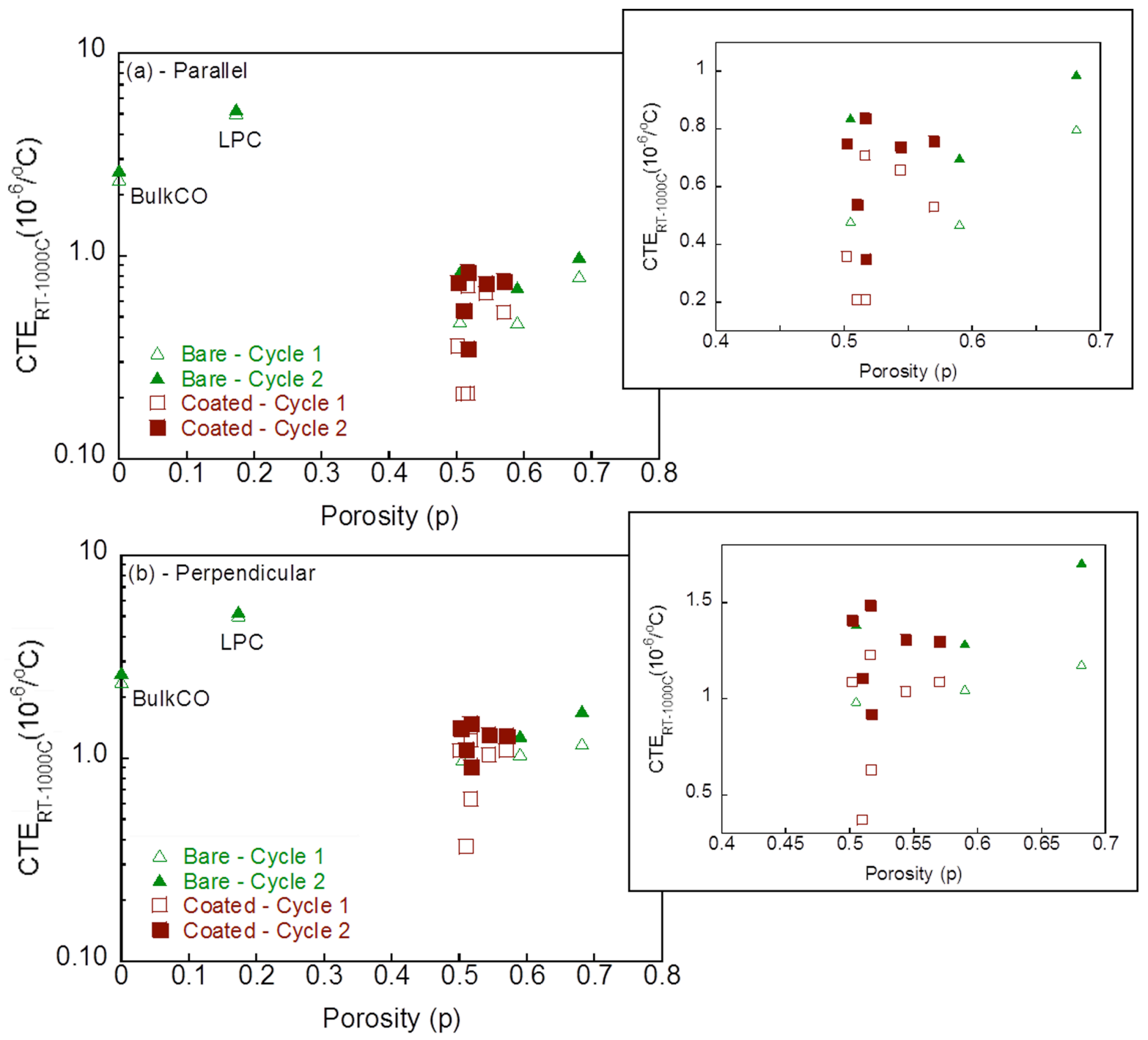
Figure 9

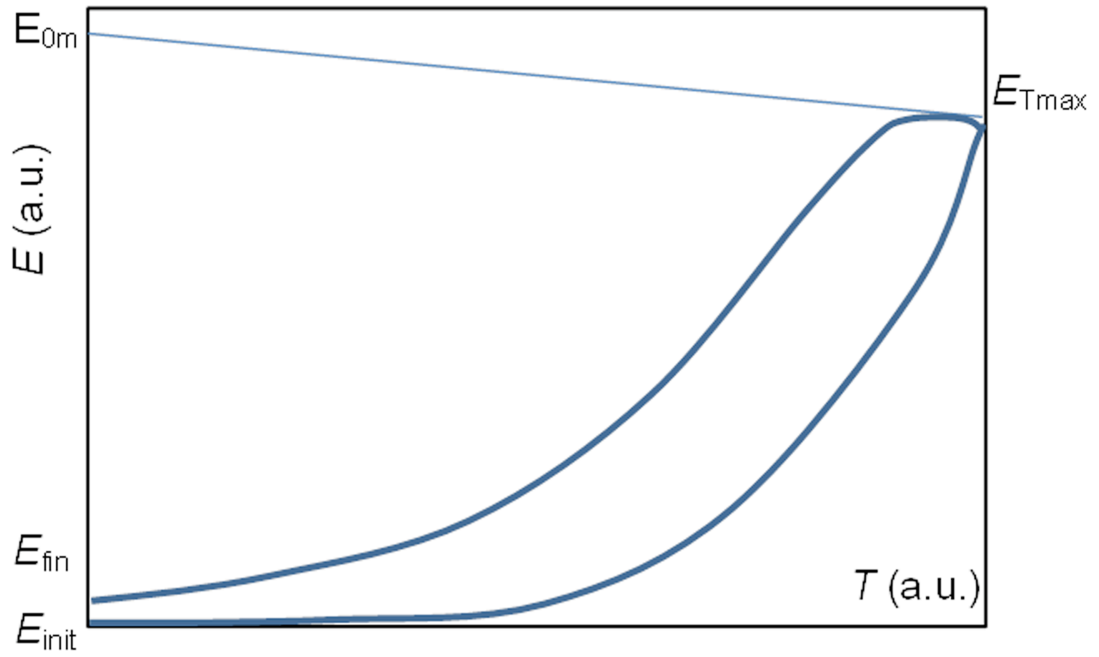


Figure 10

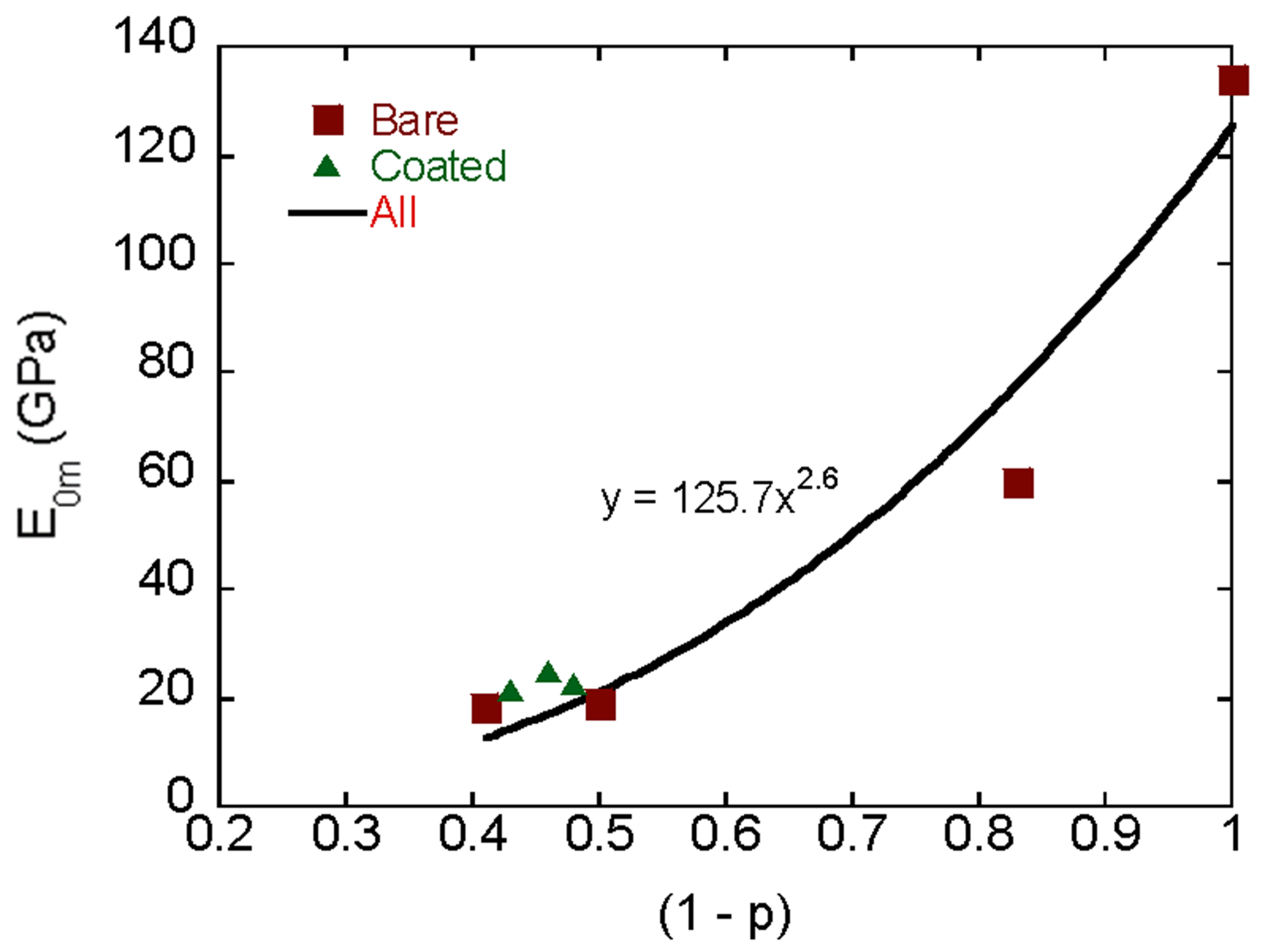


Figure 11

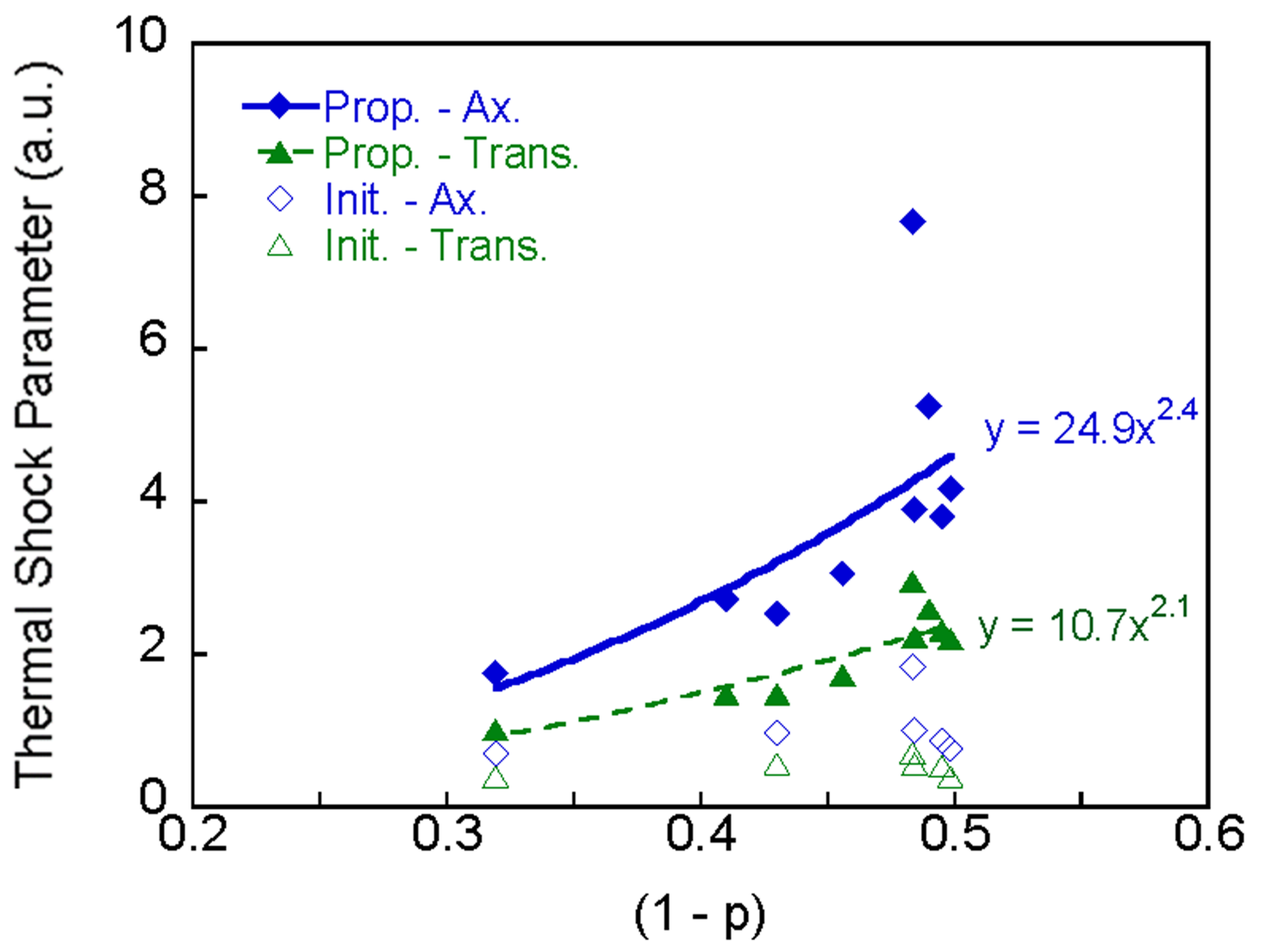

